\title{
An in vitro experiment to simulate how easy tablets are to swallow
}

\author{
M.Marconati ${ }^{\mathrm{a}}$, S.Raut $^{\mathrm{a}}$, A.Burbidge ${ }^{\mathrm{b}}$, J.Engmann ${ }^{\mathrm{b}}$, M.Ramaioli $^{\mathrm{a}}$ \\ ${ }^{a}$ Department of Chemical and Process Engineering, Faculty of Engineering and Physical \\ Sciences, University of Surrey, Guildford, GU2 7XH, United Kingdom \\ ${ }^{b}$ Nestlé Research Center, Vers-chez-les-Blanc 44, 1000 Lausanne 26, Switzerland
}

\begin{abstract}
The compliance of patients to solid oral dosage forms is heavily conditioned by the perceived ease of swallowing, especially in geriatric and pediatric populations. This study proposes a method, based on an in vitro model of the human oropharyngeal cavity, to quantitatively study the oral phase of human swallowing in presence of single or multiple tablets. The dynamics of swallowing was investigated varying the size and shape of model tablets and adjusting the applied force to the mechanical setup to simulate tongue pressure variations among individuals. The evolution of the velocity of the bolus, the oral transit time, and the relative position of the solid oral dosage form within the liquid bolus were measured quantitatively from high speed camera recordings. Whenever the solid dosage forms were big enough to interact with the walls of the in vitro oral cavity, a strong effect of the volume of the medication in respect of its swallowing velocity was observed, with elongated tablets flowing faster than spherical tablets. Conversely, the geometrical properties of the solid oral dosage forms did not significantly affect the bolus dynamics when the cross section of the tablet was lower than $40 \%$ of that of the bolus. The oral phase of swallowing multiple tablets was also considered in the study by comparing different sizes while maintaining a constant total mass. The predictive power of different theories was also evaluated against the experimental results, providing a mechanistic interpretation of the dynamics of the in vitro oral phase of swallowing. These findings and this approach could pave the way for a better design of solid oral medications to address the special needs of children or patients with swallowing disorders and could help designing more successful sensory evaluations and clinical studies.
\end{abstract}

Keywords: Bolus, Swallowing, Capsules, Tablets, Solid oral dosage forms, Oral cavity, Palate.

\footnotetext{
*Corresponding author. Tel.: 004401483684601

Email address: m.marconati@surrey.ac.uk (M.Marconati)
}

Preprint submitted to International Journal of Pharmaceutics 


\section{Introduction}

Deglutition is a fast and complex process, involving bolus transport from the oral cavity to the esophagus without compromising the functionality of the airway. From the clinical perspective, swallowing is usually divided into an oral

5 phase, a pharyngeal phase and an esophageal phase that are subsequent but nonindependent from one another (Leonard and Katerine, 2008). The swallowing reflex is first triggered by the motion of the tongue and is then accomplished by involuntary nerve impulses that provide protection of the airway. The bolus is safely guided through the glossopalatal junction (GPJ) to the upper esophageal sphincter (UES), where progressive peristaltic contractions lead it through the esophagus to the lower esophageal sphincter (LES). The overall process, starting from the first preparatory phase, in which the food bolus is chewed and wetted with saliva, until the latter esophageal phase, involves the motion of more than 40 pairs of intrinsic and extrinsic muscles (Groher, 2016). Swallowing is therefore

15 a precisely timed process and the typical transit times for a liquid bolus to pass through the pharynx is of the order of 2 seconds, while it takes less than 6 seconds to reach the stomach (Brotherman et al., 2004). While reviewing the mechanisms controlling swallowing, the roles of the tongue and the laryngeal musculature, in ensuring the correct pressure driving force to allow for a safe 20 swallow, have been highlighted (Groher, 2016). In particular, the importance of lingual coordination in the preparatory and oral phase of deglutition cannot be underestimated: the high mobility of the tongue, ensured by its set of extrinsic and intrinsic muscles, gives it several degrees of freedom to shape, hold and ultimately propel the bolus into the oropharynx.

25 Lack of tongue coordination can therefore lead to an alteration of the normal swallowing sequence that can compromise part of the time sequence of mechanisms held in place to protect the trachea from food and liquid penetration. Patients affected by swallowing disorders have to strictly control their eating habits, for instance by properly adjusting the texture of the food and drinks so consumed. The correct oral drug therapy for these patients, for which comorbidities are common, has to deal with the low acceptance for classical solid oral dosage forms that could become trapped in the larynx folds, leading to a potential risk of choking and triggering local inflammations, esophagitis, and ulceration (FDA, 2013). Similar challenges in the oral administration route of 35 solid formulations are interestingly found also in different age subsets, such as adolescents and pediatric populations for which the swallowing threshold has to be considered by both the practitioner and the caregiver (Liu et al., 2014 . Stegemann et al., 2012, Mistry and Batchelor, 2017).

Although oral formulations and novel solid oral dosage forms, such as orodis-

40 perisble and mucoadhesive tablets, have been developed and commercialized, capsules and tablets still remain the most common oral drug delivery forms (FDA, 1997, Slavkova and Breitkreutz, 2015), by virtue of the longer stability of the active pharmaceutical ingredient (API) and the higher standardization of the tableting process. The practice of dispersing crushed tablets into thickened

45 liquids, jelly, or food, can however change significantly the pharmacokinetics 
and bioavailability of some solid oral dosage forms (Salmon et al., 2013, Stubbs et al., 2008, Fields et al., 2015, Manrique et al., 2014 |Radhakrishnan, 2016).

Size and shape are deemed the most important reasons that limit acceptability of solid oral dosage forms (FDA, 2013; Schiele et al., 2015). Aspiration so and choking during the oropharyngeal phase of deglutition become increasingly common with increasing the size of solid oral dosage forms (Kelly et al. 2010). Studies revealed that the level of acceptability of an oral medication, albeit dependent upon the age subset, is greatly reduced when its diameter is above $8 \mathrm{~mm}$ (Brotherman et al. 2004). It has also been shown that size is a major 55 player in determining the esophageal transit time, smaller tablets flowing faster (Brotherman et al., 2004, Yamamoto et al., 2014, Liu et al., 2014). Concerning the dynamics of the pharyngeal phase of swallowing, no significant variations were observed when swallowing small enough solid oral dosage forms $(\mathrm{d}=2 \mathrm{~mm})$ compared to the case of swallowing homogeneous liquids (Ren et al., 1996).

60 There is however a comparable lack of studies on the effect of size of tablets on the duration of the oral phase of swallowing. The role of tongue propulsion in the first stages of deglutition was briefly discussed by Yamamoto et al. while investigating the behavioral performance of swallowing tablets in 12 subjects. In their report, the authors speculated that the difference in flow rate between 65 tablets and liquid vehicle may be the cause for the failure of the first swallowing attempt, leading the patient to take further sips to correctly transfer the oral medication from the oral cavity to the esophagus (Yamamoto et al. 2014). Hey et al. also found that administration of solid oral prescriptions in a single swallow might more easily leave the tablet lag the pharynx, while taking an identical 70 solid dose while drinking $100 \mathrm{~mL}$ of water effectively reduces the transit time of the tablet (Hey et al. 1982 ). The difficulty in tablet swallowing and the delay in their organogastric transit is much accentuated by the potential inability of some patients to drink larger amount of water or drinks in large sips (Stegemann et al. 2012).

75 Other than size, particle shape is also very important factor to be considered in tablet design. Previous reports suggest that prolate (i.e. axially elongated) tablets are easier to swallow and have faster esophageal transit times than oblate (i.e. flattened) for the same delivered dose of medication (Hey et al., 1982 . Schiele et al., 2015, Liu et al., 2014) and capsules are generally preferred to and

so tablets (Overgaard et al., 2001). On the other hand, it was also observed that more elongated tablets and capsules have a greater tendency to adhere and stick to the esophageal epithelium than biconvex and less elongated tablets, hence increasing the risk of irritating the esophageal mucosa (Wilson et al. 2000). Behavioral tests seem however to suggest the preference of panelists towards 5 oblong shapes which has not yet been mechanistically explained in terms of oral dynamics.

Factors such as density and surface coating were also among the factors considered to study the swallowability and the esophageal transit of tablets and capsules (Liu et al. 2014). Channer and Virjee showed that the esophageal 9o transit time of capsules size 0 , measured with the patients in a standing position, noticeably decreased when increasing their filling density (Channer and Virjee. 
1986) while Kasashi et al. found no statistical significant difference in the oral transit times in respect of the density for small $(0.24 \mathrm{~mL})$ and medium sized $(0.60 \mathrm{~mL})$ capsules (Kasashi et al. 2011$)$. In general, several reports have 95 proved tablet coating improves the acceptability in patients (Liu et al., 2014). Hey et al. were among the first to demonstrate that small coated oval tablets are swallowed more easily than uncoated oval tablets when consumed with an equal volume of water (Hey et al. 1982). The type of film coating can also greatly affect the tendency for solid oral formulations to adhere to the esophageal 2014. Furthermore coating also can affect other factors that contribute to patient acceptance, such as palatability and smell. The latter being a factor of paramount acceptance of solid oral dosage forms in children, as several aids have been developed ranging from in situ coating for tablets to lubricating flavored 105 gels containing glycerol to be applied to the back of the mouth prior to taking the medication (Diamond and Lavallee, 2010).

Finally, Lopez et al. highlighted the need for quantitatively assessing the ease of swallowing of novel types of solid oral dosage forms, such as mini-tablets and granulates, that specifically aim at optimally tailoring the dose of API to 110 pediatric and adolescent patients' body weight or age (Lopez et al., 2015). Oral liquid formulations indeed constitute the most widely used oral forms in pediatrics (Liu et al., 2014). Preliminary clinical studies showed a non-significant difference in acceptability in newborns between a $15 \%$ glucose syrup and a single mini-tablet of $\mathrm{d}=2 \mathrm{~mm}$ (Klingmann et al., 2015). In the report however the volume and rheology of the suspending liquid vehicles was not discussed in relaxation to that of the syrup. Another clinical research showed that small tablets $(\mathrm{d}=3 \mathrm{~mm})$ can be easily swallowed by children from 2 to 6 years of age (Thomson et al. 2009). A study involving 124 children aged 6 to 11 years, also demonstrated a high acceptability towards ingestion of a flat round tablet of $\mathrm{d}=7$

$120 \mathrm{~mm}$, especially upon training (Meltzer et al. 2006). Swallowing performance of multiple tablets in children has been subject of few studies, as reviewed by Mistry \& Batchelor (Mistry and Batchelor, 2017). It was shown that the acceptable number of tablets per unit dose depends both on the diameter of the tablet and the age of the patient (Mistry and Batchelor, 2017; Kluk et al., 2015). Improve125 ment in children compliance when taking mini-tablets was achieved dispersing the tablets into flavored liquids jelly, as proposed by Jaganiet al. (Jagani et al., 2016) and Kluk et al. (Kluk et al., 2015). However the same study, although confirming the high palability of mini-tablets, showed lower acceptability and a higher occurrence of chewing when the number of mini-tablets $(\mathrm{d}=3 \mathrm{~mm})$ was increased (Kluk et al., 2015). Hayakawa et al. showed that the ease of swallowing of multiple tablets as a unit dose decreases with their number, in particular administration of a single conventional tablet of $\mathrm{d}=8 \mathrm{~mm}$ was perceived easier to swallow than an identical mass of 10 mini-tablets (Hayakawa et al., 2016).

Based on all these premises, this study aims at presenting a novel method to 135 quantitatively assess the role of the physical properties of tablets, such as their size, shape and number, on the oral dynamics of swallowing. In order to lay the basis for a mechanistic understanding of these phenomena, the study considered 
an in vitro model of the oral cavity which had been previously validated against in vivo measurement while evaluating the effect of bolus rheology (Hayoun et al. 2015. Mowlavi et al., 2016).

\section{Materials and methods}

\subsection{Materials}

Different sizes and shapes of hard particles, representative of solid oral dosage forms, were considered to compare the relative difference in the measured in vitro oral transit time and bolus velocity. The effect of size for different solid oral dosage forms was studied using calibrated polypropylene spheres (The Precision Plastic Ball Company Ltd, Addingham, UK) of diameter ranging from 4.8 to $10 \mathrm{~mm}$ and smooth surface finishing. By using those model shapes the degree of freedom of initial particle orientation in respect of the bolus was removed, allowing for generalization of the results. More realistic model shapes of pharmaceutical tablets were instead used to assess the impact of the solid oral medication geometry on the oral flow. These consisted of ellipsoids of revolution with volumes comparable to either a $8 \mathrm{~mm}$ or a $10 \mathrm{~mm}$ sphere (Table 1). To this extent, elongated particles were designed and 3D printed by UV curing (ProJect ${ }^{T M}$ MJP 3600, 3D Systems Inc., San Diego, CA, USA). The shape of both flattened (i.e. oblate) and elongated (i.e. prolate) spheroids was consistently described through their aspect ratio (AR), defined by the ratio of polar and equatorial semiaxis (Fig 1). Density was measured by gas pycnometry (AccuPyc pycnometer 1330, Micrometrics Instrument Corp., Norcross, GA, USA) for both spherical and elongated tablets, obtaining values of $\rho_{S}=850 \pm 50 \mathrm{~kg} \mathrm{~m}^{-3}$ and $1100 \pm 50 \mathrm{~kg} \mathrm{~m}^{-3}$ respectively. The impact of tablet density in the oral swallowing dynamics was not considered an important experimental variable as previous in vivo studies already proved (Kasashi et al. 2011). Similarly, the specific density of different liquid vehicles was tested in vitro without showing 165 any significant variation in the bolus velocity (Mowlavi et al., 2016).

Moreover, in order to further explore the dynamics of swallowing of elongated solid oral dosage forms, empty hydroxypropylmethyl cellulose (HPMC) capsules size 00 and size 3 were purchased from Bulk Powders (Sports Supplements Ltd, Colchester, Essex, UK) and filled with sucrose so that their density would match 170 that of the spherical beads $\left(\rho_{S}=850 \pm 50 \mathrm{~kg} \mathrm{~m}^{-3}\right)$. The volume of a $\mathrm{d}=8 \mathrm{~mm}$ sphere is comparable to a size 3 capsule and the volume of a $\mathrm{d}=10 \mathrm{~mm}$ sphere is almost double. A much bigger size 00 capsule was also considered as a limiting case, given that it is the maximum capsule size recommended by the Food and Drug Administration (FDA, 2013).

175 To assess the dynamics of the bolus in presence of multiple tablets, experiments were also run with several mono-dispersed spheres. In this set of tests, the number of solid oral medications was varied while maintaining constant the solid volume fraction of $\phi=0.08 \mathrm{v} / \mathrm{V}$, corresponding to the dose of a single $\mathrm{d}=10 \mathrm{~mm}$ spherical tablet.

$180 \quad$ Glycerol (Sigma-Aldrich, CAS Number 56-81-5) was primarily used as liquid carrier, although a number of tests were also carried out using orange juice 
Table 1: Geometry of the solid oral dosage forms used in the in vitro experiments to model swallowing of a single solid oral dosage form.

\begin{tabular}{|c|c|c|c|c|c|}
\hline & $\begin{array}{l}\text { Tablet } \\
\text { shape }\end{array}$ & $\begin{array}{c}\text { Characteristic } \\
\text { size }(\mathrm{d} \text { or } \mathrm{L} \times \mathrm{H})\end{array}$ & $\begin{array}{l}\text { Tablet to bolus } \\
\text { cross section }\end{array}$ & Volume & Weight \\
\hline \multirow{4}{*}{$\begin{array}{l}\text { Effect of } \\
\text { tablet size }\end{array}$} & Sphere & $\mathrm{d}=4.8 \mathrm{~mm}$ & $15 \%$ & $0.06 \mathrm{~mL}$ & $50 \mathrm{mg}$ \\
\hline & Sphere & $\mathrm{d}=6.4 \mathrm{~mm}$ & $28 \%$ & $0.13 \mathrm{~mL}$ & $120 \mathrm{mg}$ \\
\hline & Sphere & $\mathrm{d}=8 \mathrm{~mm}$ & $44 \%$ & $0.27 \mathrm{~mL}$ & $240 \mathrm{mg}$ \\
\hline & Sphere & $\mathrm{d}=10 \mathrm{~mm}$ & $68 \%$ & $0.52 \mathrm{~mL}$ & $460 \mathrm{mg}$ \\
\hline \multirow{5}{*}{$\begin{array}{c}\text { Effect of } \\
\text { tablet shape: } \\
\text { volume of } \\
0.27 \mathrm{~mL}\end{array}$} & $\begin{array}{c}\text { Oblate } \\
\text { spheroid }\end{array}$ & $\begin{array}{c}12.7 \times 3.2 \mathrm{~mm} \\
\mathrm{AR}=0.25\end{array}$ & $28 \%$ & $0.27 \mathrm{~mL}$ & $310 \mathrm{mg}$ \\
\hline & $\begin{array}{l}\text { Prolate } \\
\text { spheroid }\end{array}$ & $\begin{array}{c}10.5 \times 6.9 \mathrm{~mm} \\
\mathrm{AR}=1.5\end{array}$ & $33 \%$ & $0.27 \mathrm{~mL}$ & $310 \mathrm{mg}$ \\
\hline & $\begin{array}{c}\text { Prolate } \\
\text { spheroid }\end{array}$ & $\begin{array}{c}14.7 \times 5.9 \mathrm{~mm} \\
\mathrm{AR}=2.5\end{array}$ & $24 \%$ & $0.27 \mathrm{~mL}$ & $310 \mathrm{mg}$ \\
\hline & $\begin{array}{l}\text { Prolate } \\
\text { spheroid }\end{array}$ & $\begin{array}{c}18.4 \times 5.3 \mathrm{~mm} \\
\mathrm{AR}=3.5\end{array}$ & $19 \%$ & $0.27 \mathrm{~mL}$ & $310 \mathrm{mg}$ \\
\hline & $\begin{array}{c}\text { Capsule } \\
\text { size } 3 \\
\end{array}$ & $\begin{array}{c}15.5 \times 5.8 \mathrm{~mm} \\
\mathrm{AR}=2.80\end{array}$ & $22 \%$ & $0.27 \mathrm{~mL}$ & $280 \mathrm{mg}$ \\
\hline \multirow{4}{*}{$\begin{array}{c}\text { Effect of } \\
\text { tablet shape: } \\
\text { volume of } \\
0.52 \mathrm{~mL}\end{array}$} & $\begin{array}{c}\text { Oblate } \\
\text { spheroid }\end{array}$ & $\begin{array}{c}15.8 \times 3.9 \mathrm{~mm} \\
\mathrm{AR}=0.25\end{array}$ & $42 \%$ & $0.52 \mathrm{~mL}$ & $610 \mathrm{mg}$ \\
\hline & $\begin{array}{c}\text { Prolate } \\
\text { spheroid }\end{array}$ & $\begin{array}{c}13.1 \times 8.7 \mathrm{~mm} \\
\mathrm{AR}=1.5\end{array}$ & $52 \%$ & $0.52 \mathrm{~mL}$ & $610 \mathrm{mg}$ \\
\hline & $\begin{array}{c}\text { Prolate } \\
\text { spheroid }\end{array}$ & $\begin{array}{c}18.4 \times 7.4 \mathrm{~mm} \\
\mathrm{AR}=2.5\end{array}$ & $37 \%$ & $0.52 \mathrm{~mL}$ & $610 \mathrm{mg}$ \\
\hline & $\begin{array}{l}\text { Prolate } \\
\text { spheroid }\end{array}$ & $\begin{array}{c}23.1 \times 6.6 \mathrm{~mm} \\
\mathrm{AR}=3.5\end{array}$ & $30 \%$ & $0.52 \mathrm{~mL}$ & $610 \mathrm{mg}$ \\
\hline $\begin{array}{c}\text { Effect of } \\
\text { tablet shape }\end{array}$ & $\begin{array}{l}\text { Capsule } \\
\text { size } 00\end{array}$ & $\begin{array}{c}32.5 \times 8.5 \mathrm{~mm} \\
\mathrm{AR}=2.80\end{array}$ & $49 \%$ & $0.95 \mathrm{~mL}$ & $900 \mathrm{mg}$ \\
\hline
\end{tabular}

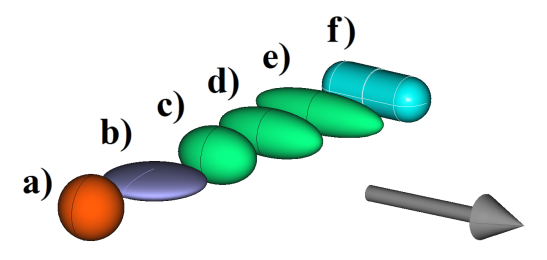

Figure 1: From left to right different shapes of solid oral dosage forms considered: a) sphere b) oblate spheroid of $\mathrm{AR}=0.25$, c) prolate spheroid of $\mathrm{AR}=1.5$, d) prolate spheroid of $\mathrm{AR}=2.5$, e) prolate spheroid of $\mathrm{AR}=3.5, \mathrm{f}$ ) capsule size 3 . The arrow points the direction of swallowing. 
from concentrate (Tesco Stores Ltd., Welwyn Garden City, Hertfordshire, UK). In both cases traces of a red dye $(0.02 \% \mathrm{w} / \mathrm{w})$ were added to enhance the image contrast. The density of the two liquids were measured using a graduated cylinder obtaining values of $\rho_{L}=1250 \pm 20 \mathrm{~kg} \mathrm{~m}^{-3}$ and $1040 \pm 30 \mathrm{~kg} \mathrm{~m}^{-3}$ for glycerol and orange juice respectively. The liquid volume used in the experiments was 6 $\mathrm{mL}$, consistently with previous studies (Hayoun et al., 2015) and comparable to in vivo values reported in literature (Alsanei, 2015: Kluk et al. 2015). All the experiments were performed at $22 \pm 1^{\circ} \mathrm{C}$ and, at this temperature, the rheology

190 of the two liquid vehicles was characterized in compliance with ISO standard 3219 with a controlled stress-controlled rheometer (Model UDS 200, Paar Physica, Germany). Both the glycerol solution and the orange juice exhibited a Newtonian behavior over the range of shear rates considered $\left(1-500 \mathrm{~s}^{-1}\right)$ and their viscosity was $\mu=1.05 \pm 0.05 \mathrm{~Pa}$ s and $\mu=0.03 \pm 0.01 \mathrm{~Pa}$ s respectively.

\subsection{The in vitro swallowing model}

The experimental setup used to study the oral phase of swallowing simplified the in vivo flow pattern considering a bi-dimensional projection in the sagittal plane. A thin, flat and freely deformable membrane, obtained by sealing together two polyethylene (PE) sheets, was stuck to the rigid surface mimicking the human palate, and used to constrain and hold the bolus. The propulsion of the bolus was instead generated by a roller, sealing anteriorly the membrane filled with the liquid and the solid oral dosage forms. The thin membrane and the roller provided together the two lingual functions of bolus containment and propulsion. The rigid roller was supported by a pivoting arm, attached to a re205 volving shaft driven through a set of hanging weights, as schematically depicted in Fig. 2. Upon triggering of the experiment, the roller moves, following the curved path, squeezing the liquid bolus through the PE membrane. A theoretical model, derived in Appendix A, was used to describe the dynamics of the in vitro setup and relate the velocity of the bolus tail to the rheology of the liquid carrier and the size and number of solid oral dosage forms. Variability of tongue applied pressure among individuals was accounted for by adjusting the weight driving the rotation of the pivoting arm. In this study roller driving forces $(\mathrm{F})$ of 2, 2.7, and $4 \mathrm{~N}$ were used, corresponding to applied torques of 57, 73 and $108 \mathrm{mNm}$ respectively. These driving forces generated maximum pressures on 215 the bolus tail of approximately 11,15 , and $21 \mathrm{kPa}$, consistently with in vivo data from the literature (Hayoun et al., 2015). Results from the same in vitro model were successfully validated against in vivo ultrasound measurements with thickened fluids (Mowlavi et al., 2016) and the swallowing simulator matched well the in vivo bolus dynamics when applying a force of $2 \mathrm{~N}$.

\subsection{Methods}

The different solid oral dosage forms listed in Table 1 were first incorporated into the suspending liquid carrier and subsequently the bolus was pushed manually into the membrane through its anterior opening (Fig. 2). The initial position of the tablets in the bolus is essentially dictated by buoyancy as the 

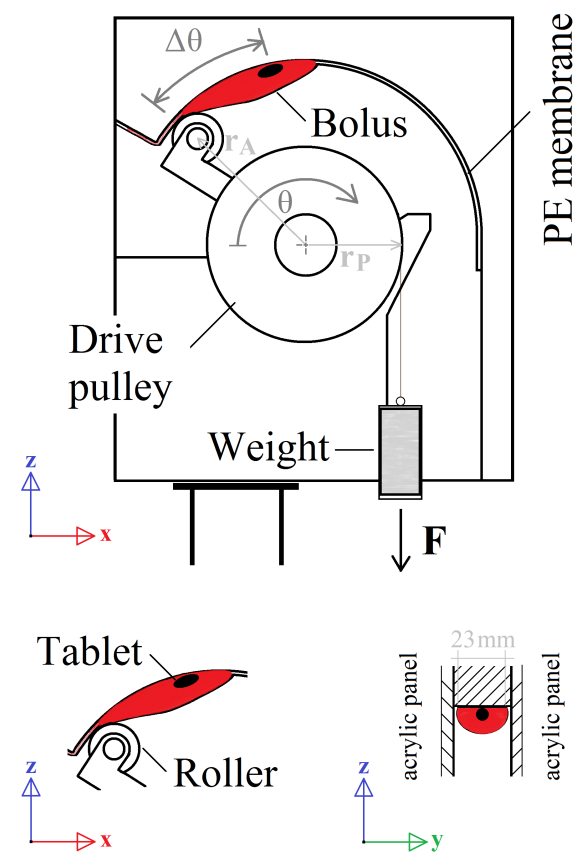

Figure 2: Schematics of the in vitro setup.

225 Solids were located centrally within the bolus cross section in order to avoid direct contact with the walls of the membrane. Moreover, non spherical tablets and capsules were consistently aligned with the longitudinal axis of the bolus, in order to present their smallest cross section in the direction of swallowing 230 (Fig. 1).

The roller movement was triggered by releasing a pin and lateral images were recorded using a fast camera (model ac1920-155 um, Basler, Germany) at 150 frames per second. The dynamics of the bolus was measured from the video recordings: image processing tools were used to extract the instantaneous position of the roller (corresponding to the bolus tail), of the bolus center of mass, of the tablet center of mass, and to measure the bolus area. The instantaneous velocity of the roller was calculated from the time dependent roller positions by numerical differentiation. Results were compared to the theoretical predictions obtained considering the system dynamics and the drag force defined in Eq. A.8 and A.9. Finally, the relative position of the solid oral dosage forms within the bolus was quantified by the difference $(\Delta \theta)$ of the angular positions of the bolus tail and of the tablet, as schematically illustrated in Fig. 2. Decreasing $\Delta \theta$ indicated that the tablet was slower than the liquid carrier and moved towards the tail of the bolus, while constant $\Delta \theta$ indicated that it moved at the same 
velocity as the rest of the bolus.

$$
\Delta \theta=\theta_{\text {tablet }}-\theta_{\text {roller }}
$$

Three repeats, in randomized order, were taken per each set of experimental variables to assess the variability and robustness of the in vitro setup to external disturbances, such as slight variations in the initial position of the solid oral dosage forms within the liquid bolus, or minor differences in the shape of the 235 PE membranes.

\section{Results and discussion}

The experiments aimed at understanding the effect of solid oral dosage size, shape and number on the oral swallowing dynamics while varying the external applied force.

\subsection{In vitro swallowing of single tablets}

The effect of tablet size on the dynamics of the mechanical system was initially investigated. The applied force and the initial position of the spherical tablet were consistent in all experiments, as illustrated in Fig. 3 and the characteristic oral transit time was extracted from the experimental video recordings, marking the frame at which the front of the peristaltic flow left the plastic membrane (front out-FO) and the instant at which the roller hit the stopper leading the tail of the bolus to exit the plastic membrane (tail out-TO). Average values and standard deviations were computed based on three repetitions of each experiment, as listed in Table 2 .

From the snapshots in Fig. 3 and the data listed in Table 2 , it can be seen that larger solid oral dosage forms had a slightly delayed FO and TO with respect of smaller spherical tablets. More generally, the delay between these events both depended on the size of solid oral dosage forms and on the applied load to the system. The range of values for the characteristic in vitro 255 swallowing listed in Table 2 well compares with the typical values of oral transit times reported in literature when considering swallow of homogeneous thickened fluids. When considering administration of solid oral dosage forms, only a few references are found in literature: Kasashi et al. provide slightly longer oral transit times (1.14-2.23 s), based on videofluoroscopy assessment of capsule swallowing (Kasashi et al., 2011), while EMG recordings from Yamamoto et al. show a one-fold increase in the swallowing duration when taking a large $\mathrm{d}=9$ mm biconvex tablet compared to the water control (Yamamoto et al., 2014), but a less significant increase for smaller tablets.

The velocity profiles obtained after numerical differentiation of the time 265 dependent roller angular positions are plotted in the following figures until bolus front out (FO), consistently to the approach followed by Hayoun et al. (Hayoun et al. 2015).

The results obtained with different solid oral dosage forms shapes and sizes were compared to the theoretical predictions obtained considering the system 

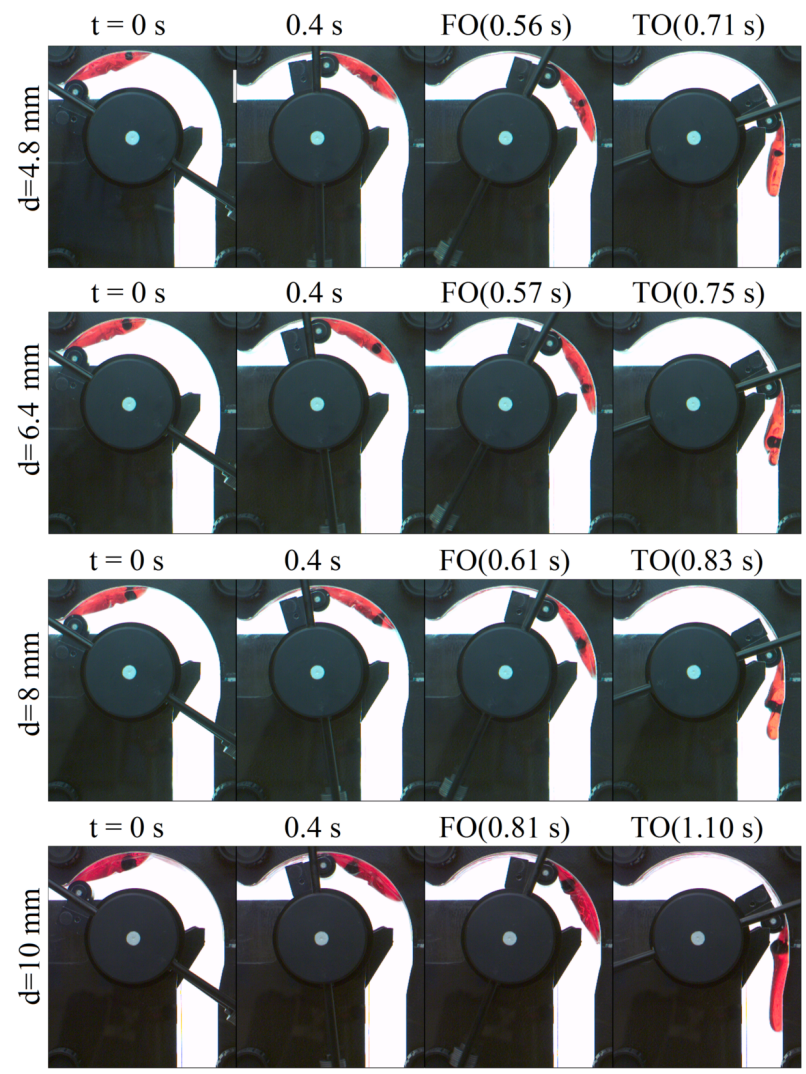

Figure 3: Screenshots of in vitro experiments using a $2 \mathrm{~N}$ load, a $1.05 \mathrm{~Pa}$ s Newtonian liquid carrier and single spherical tablets having different diameters. The pictures in the third and fourth columns are respectively taken when the bolus front leaves the membrane (FO) and when the tail of the bolus leaves the membrane (TO). 


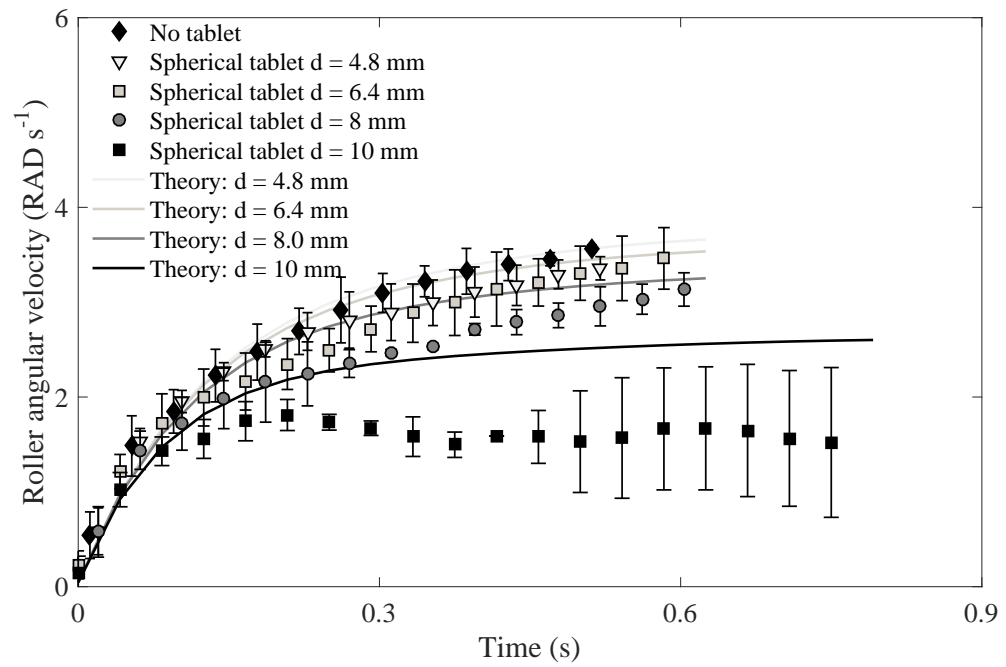

Figure 4: Roller velocity profiles for model spherical tablets of $\mathrm{d}=4.8,6.4,8.0$ and $10 \mathrm{~mm}$ using a $2 \mathrm{~N}$ load and a $1.05 \mathrm{~Pa}$ s Newtonian liquid carrier. Theoretical curves are obtained using Eq. A.8

dynamics and the drag force defined in Eq. A.8 and illustrated in the charts with thin lines.

Variations in the driving load applied to the mechanical device strongly conditioned the bolus dynamics, as discussed by Hayoun et al. (Hayoun et al., 2015). The combined effect of applied force and size for spherical solid oral 275 dosage forms is illustrated in Fig. 4 and Fig. 5. experiments at low applied forces $(2 \mathrm{~N})$ were characterized by an inertial regime, in which the angular velocity was almost linearly increasing in time, followed by a viscus regime where the drag force became predominant and effectively equilibrated the inertial force, leading to asymptotic values of bolus velocity (Fig. 4). By contrast, experiments at higher applied loads only showed the inertial regime.

The relative importance of the additional drag force induced by the presence of swallowed solids is also dependent upon the external load applied to the system. Experiments in the lowest load configuration $(2 \mathrm{~N})$ showed a moderate decrease of swallowing velocity and longer oral transit time increasing the diam-

285 eter of the suspended spherical solids. Small solid oral dosage forms were also found not to significantly alter the system dynamics, compared with the solidfree case presented by Hayoun et al., as can be appreciated from the profiles reported in Fig. 4 and 5 .

Conversely, tests with significantly bigger model tablet seem to suggest the onset of an anticipated viscous regime of significantly low angular velocity than the asymptotic values reached in clear liquid. This is especially visible at low applied forces, as illustrated in Fig. 4. Conversely, at the highest load (4 N), no significant effect of the tablet diameter was observed, although the in vitro 


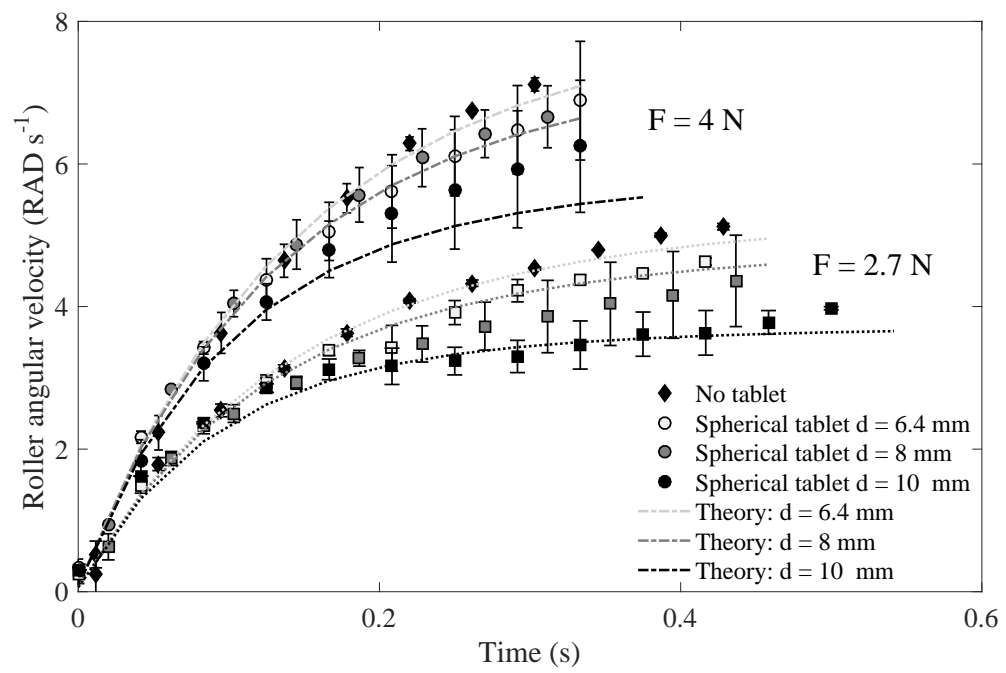

Figure 5: Roller velocity profiles for model spherical tablets of $\mathrm{d}=6.4,8$ and $10 \mathrm{~mm}$ at 2.7 and $4 \mathrm{~N}$ load and a $1.05 \mathrm{~Pa}$ s Newtonian liquid carrier. Theoretical curves are obtained using Eq. A.8

Table 2: Characteristic oral transit times measured with the mechanical model when swallowing a single spherical tablets in a $1.05 \mathrm{~Pa}$ s liquid carrier (glycerol).

\begin{tabular}{ccll}
\hline Applied force & Tablet diameter & $\begin{array}{c}\text { Average bolus FO } \\
(\mathrm{SD} \mathrm{n}=3)\end{array}$ & $\begin{array}{c}\text { Average bolus TO } \\
(\mathrm{SD} \mathrm{n}=3)\end{array}$ \\
\hline \multirow{2}{*}{$2 \mathrm{~N}$} & $4.8 \mathrm{~mm}$ & $0.58(0.03) \mathrm{s}$ & $0.73(0.02) \mathrm{s}$ \\
& $6.4 \mathrm{~mm}$ & $0.61(0.04) \mathrm{s}$ & $0.78(0.04) \mathrm{s}$ \\
& $8 \mathrm{~mm}$ & $0.64(0.03) \mathrm{s}$ & $0.82(0.02) \mathrm{s}$ \\
& $10 \mathrm{~mm}$ & $0.97(0.17) \mathrm{s}$ & $1.27(0.18) \mathrm{s}$ \\
\hline \multirow{2}{*}{$2.7 \mathrm{~N}$} & $4.8 \mathrm{~mm}$ & $0.45(0.02) \mathrm{s}$ & $0.58(0.01) \mathrm{s}$ \\
& $6.4 \mathrm{~mm}$ & $0.46(0.02) \mathrm{s}$ & $0.59(0.01) \mathrm{s}$ \\
& $8 \mathrm{~mm}$ & $0.47(0.01) \mathrm{s}$ & $0.60(0.01) \mathrm{s}$ \\
$4 \mathrm{~N}$ & $10 \mathrm{~mm}$ & $0.53(0.03) \mathrm{s}$ & $0.66(0.03) \mathrm{s}$ \\
\hline & $4.8 \mathrm{~mm}$ & $0.34(0.02) \mathrm{s}$ & $0.43(0.03) \mathrm{s}$ \\
& $6.4 \mathrm{~mm}$ & $0.34(0.02) \mathrm{s}$ & $0.43(0.02) \mathrm{s}$ \\
& $8 \mathrm{~mm}$ & $0.33(0.02) \mathrm{s}$ & $0.43(0.01) \mathrm{s}$ \\
& $10 \mathrm{~mm}$ & $0.38(0.01) \mathrm{s}$ & $0.48(0.02) \mathrm{s}$ \\
\hline
\end{tabular}


transit time of the biggest sphere was still slightly slower than the others (Fig. 5). In the case of an intermediate load $(2.7 \mathrm{~N})$, results showed a comparably slow dynamics of the $\mathrm{d}=10 \mathrm{~mm}$ spherical solid, when compared to the other beads. The theory used to describe the viscous dissipation (Eq. A.8) captured well the transition between inertial to viscous regimes in absence of significant solid-solid interaction between the tablet and the sidewalls (i.e. smaller solids). Conversely,

300 a noticeable under-prediction of drag force was observed for the largest sphere at the lowest driving force where the friction between tablet and PE tube, although mitigated by the lubricating effect of glycerol, played a significant role in the swallowing dynamics (Fig. 4). This both outlines the limits of the simple theoretical model assumed by the study and the relevance of using in vitro 305 experiments to evaluate the effect of different shapes of solid oral dosage forms.

The examination of the relative motion of the tablet within the suspending liquid vehicle was considered in light of the study of peristaltic model flows and the experimental observation of Yamamto et al. that commented on the different flow rate between liquid and solid portions of the swallowed bolus. The angular 310 distance between the position of the roller and the position of the center of mass of the tablet was quantified through the value of $\Delta \theta$. This parameter, not being directly comparable to a specific theoretical formulation for the field of motion here considered, leads to a more qualitative interpretation, compared to the much more quantitative information obtained from the roller velocity profiles 315 of Fig. 4 and Fig. 6 . Nonetheless the typical average profiles of $\Delta \theta$ reported, as a function of the tablet size and applied load, in Fig. 8, give some coherent results. The profiles show good consistency of initial positioning of the beads, that were always placed in proximity to the bolus front with the sole exception of the largest spherical tablet, that instead was positioned slightly rearward in 320 order to limit the occurrence of liquid leaking before triggering the experiment. At low applied force, Fig. 8 indicates that both the 6.4 and the $8 \mathrm{~mm}$ spherical tablets did not move significantly within the bolus, as the initial angle was preserved throughout the bolus trajectory. Conversely, a significant reduction in $\Delta \theta$ was observed in both the $\mathrm{d}=4.8 \mathrm{~mm}$ and $\mathrm{d}=10 \mathrm{~mm}$ spheres that lagged 325 toward the tail of the bolus. This result somehow confirms that small objects are less efficiently transported by peristalsis, as indicated in previous works in that field (Fauci, 1992, Hung and Brown, 1976). On the other hand, the relative backward motion of the biggest sphere, unexplained in terms of simple peristaltic transport, is instead driven by the friction with the wall membrane. In this case 30 the liquid carrier, under the imposed squeezing action of the roller, was able to flow cross the free portion of the bolus unoccupied by the solid oral dosage form lagging the spherical tablet behind. Increasing the external applied load did not lead to significant changes in the tablet relative position: the smallest solid still slides backwards, whist no noticeable variations in relative position in 335 respect of the bolus tail are observed for both the intermediate size spherical tablets $(\mathrm{d}=6.4$ and the $\mathrm{d}=8 \mathrm{~mm})$.

Based on these in vitro observations, the backward motion of the smallest, or very large solids might limit the active volume of liquid available to wash them out during the pharyngeal and esophageal phase of swallowing and also 

tongue propelling the bolus. Following this hypothesis, the extent of mechanical solicitation on the tongue apex and dorsum will also be dependent upon the size and density of the solid oral prescription and the level of its surface finishing. The lack of comparable videofluoroscopy images does currently not allow to

345 confirm this claim, although the conclusion from Yamamto et al., seems to suggest that the difference between tablet and liquid vehicle velocity might indeed lead to the need for repeated swallows to effectively wash the tablet down the pharynx (Yamamoto et al., 2014).

The effect of shape was considered comparing results of spherical, oblate (flattened) and prolate (elongated) solid oral dosage forms (Fig. 6). The orientation of the solids in respect of the longitudinal axis of the bolus was always maintained throughout the oral trajectory. The corresponding theoretical velocity profiles were in this case computed considering the cross sectional radius of the tablet in the direction of swallowing as $R_{i}$ in Eq. A.8.

The effect of tablet shape on the bolus dynamics was more significant when the mechanical system was operated under low applied forces, as already observed when discussing the role of size for spherical solid oral dosage forms. In this condition, the tablet and capsule geometry was found to affect more significantly the dynamics of larger solid oral dosage forms (Fig. 6). The set of data 360 from in vitro swallowing at constant volumetric dose of solid oral medications (equivalent to that of a $\mathrm{d}=10 \mathrm{~mm}$ sphere) showed that there was a correlation between the cross sectional area of the swallowed solid and the rapidity of bolus transport through the oral cavity (Fig. 6). As the cross section of the tablet fell below $40 \%$ of that of the bolus, the effect of shape for spheroids became less and less important (Fig. 6a). Naturally, the increased wall interaction observed when running experiments with the largest spherical tablet likely resulted in further dissipation phenomena. Yet, the velocity profile of that solid oral dosage form was nearly identical to that of a size 00 capsule, whose volume is noticeably larger than the sphere (Fig. 6b). This consideration allows to highlight the

370 importance of optimally choosing the solid oral dosage shape in the delivery of oral medications.

When considering the set of data from experiments with tablets of equivalent volume to that of a $\mathrm{d}=8 \mathrm{~mm}$ sphere, it was found that the change in cross section did not lead to significant variations in bolus dynamics. The role of 375 tablet shape became therefore marginal. This observation is in good agreement with the clustering of the velocity profiles observed in Fig. 6.

Increasing the driving force applied to the roller led to a faster bolus dynamics that was not strongly conditioned by the tablet shape, in that case the oral transit times obtained for the elongated tablets (AR 3.5) were similar to

380 those of spherical tablets of identical volume. Moreover, the theoretical velocity profiles consistently over-predicted the experimental data of spheroidal solids. This highlights the necessity for more accurate models to account for particle shape, as the model of Eq. A.8 does not account for the length of the solid oral dosage form in the direction of swallowing, but only considers its cross sectional 385 radius. in vivo the preference of patients towards different shapes of tablets 
was comprehensively discussed by Overgaard et al. over a sample population of 331 volunteers (Overgaard et al. 2001). Based on the evaluation scheme proposed by the authors, a higher preference towards strongly arched circular shapes was preferred over oblong shapes for small tablets (approx. volume of $0.16 \mathrm{~mL}$ ), while for medium and large tablets (approx. 0.5 and $0.95 \mathrm{~mL}$ ), oblong and oval shapes were preferred over the flat circular. In particular, for the biggest size subset, thick oval shapes (i.e. prolate ellipsoid with low aspect ratios) were generally indicated as difficult to swallow, which is consistent to the poor performance observed in vitro.

The high viscosity of glycerol is close to that of oral pediatric formulations, such as paracetamol suspensions (Batchelor et al. 2015). Thickened liquids and jelly have also been used to aid tablet and mini-tablet swallowing in geriatric and pediatric patients (Kluk et al., 2015; Mistry and Batchelor, 2017). In order to assess the feasibility of using the proposed in vitro tests to characterize a wider range of liquid carriers, a concentrated orange juice was also considered. The viscosity of this carrier is considerably lower than that of glycerol but still approximately 30 times higher than water. The effect of the rheology of the liquid carrier was assessed using the largest tablets and in the lowest load configuration $(2 \mathrm{~N})$ to better capture the effect of tablet elongation, as highlighted 405 by the precedent trials in glycerol. Results show a noticeable decrease in the characteristic oral transit times (Table 3). The observation is consistent with the findings of Mowlavi et al. who assessed the role of viscosity using diluted glycerol solutions and a commercial food thickener (Mowlavi et al. 2016). Comparing the different liquids in terms of their rheology, the authors demonstrated the transition from an inertial regime, characterized by a linearly increasing bolus angular velocity during swallowing, to a viscous regime of asymptotic values of bolus velocity. Consistently to this finding, the velocity profiles obtained with orange juice, illustrated in Fig. 7, remarkably differ from those of Fig. 6b. The low viscous dissipation calculated in case of the concentrated juice predicts an 415 almost linear velocity profile not significantly dependent on the diameter of the tablet considered. Besides, experiments with concentrated juice demonstrated a stronger impact of tablet elongation compared to the weak effect observed with glycerol. Comparing the values listed in Table 3 with the velocity profiles Fig. 7 shows comparable transit times for the most elongated (AR 3.5) and the flat${ }_{420}$ test (AR 0.25) tablets. Conversely, longer transit times, higher variability and lower bolus velocities were registered for the spheroidal tablet of largest cross section (AR 1.5). A visual analysis of the corresponding tests helps identifying the cause for a similar behavior in terms of tablet friction against the sidewalls. Tablet shapes with smaller cross sections were found less likely to lag behind the 425 liquid vehicle therefore avoiding direct contact with the sidewalls. Conversely, tablets of large cross section (AR 1.5) pinch against the membrane. This results in a non monotonic roller angular velocity profile and considerably TO times, as reported in Table 3 . 
Table 3: Characteristic oral transit times at $2 \mathrm{~N}$ load for different aspect ratios of spheroidal tablets of equivalent volume to a $\mathrm{d}=10 \mathrm{~mm}$ sphere in glycerol and concentrated orange juice.

\begin{tabular}{cccl}
\hline $\begin{array}{c}\text { Liquid } \\
\text { vehicle }\end{array}$ & $\begin{array}{c}\text { Tablet } \\
\text { AR }\end{array}$ & $\begin{array}{c}\text { Average bolus FO } \\
(\mathrm{SD} \mathrm{n}=3)\end{array}$ & $\begin{array}{c}\text { Average bolus TO } \\
(\mathrm{SD} \mathrm{n}=3)\end{array}$ \\
\hline \multirow{3}{*}{ Glycerol } & 0.25 & $0.67(0.09) \mathrm{s}$ & $0.92(0.05) \mathrm{s}$ \\
& 1.5 & $0.69(0.06) \mathrm{s}$ & $0.95(0.10) \mathrm{s}$ \\
& 3.5 & $0.65(0.04) \mathrm{s}$ & $0.87(0.04) \mathrm{s}$ \\
\hline \multirow{2}{*}{ Orange juice } & 0.25 & $0.31(0.03) \mathrm{s}$ & $0.43(0.02) \mathrm{s}$ \\
& 1.5 & $0.39(0.09) \mathrm{s}$ & $1.59(0.35) \mathrm{s}$ \\
& 3.5 & $0.31(0.02) \mathrm{s}$ & $0.42(0.02) \mathrm{s}$ \\
\hline
\end{tabular}

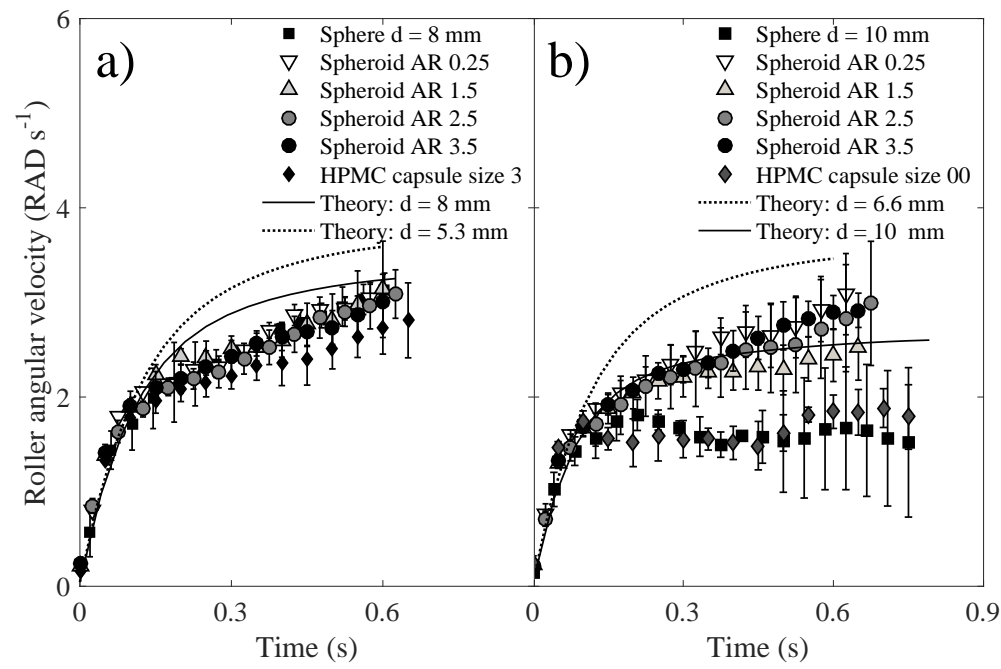

Figure 6: Effect of tablet shape using a $2 \mathrm{~N}$ load in a $1.05 \mathrm{~Pa} \mathrm{~s}$ Newtonian liquid carrier: roller angular velocity for oblate, spherical, and prolate tablets of identical volumes to that of a $d=8 \mathrm{~mm}$ (a) and $\mathrm{d}=10 \mathrm{~mm}$ sphere (b). Theoretical curves are obtained using Eq. A.8 


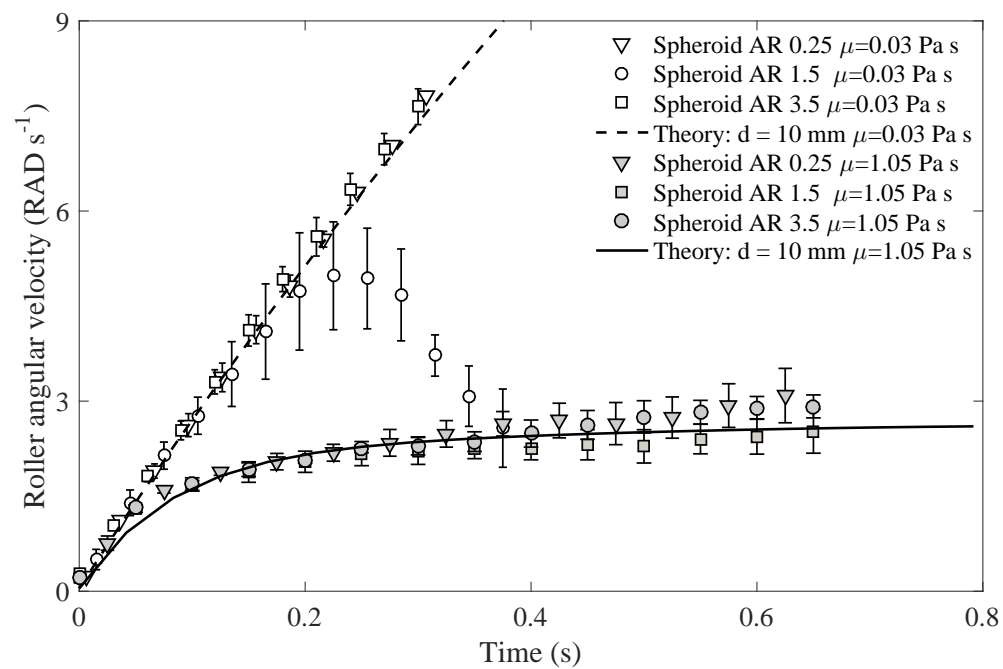

Figure 7: Effect of the carrier liquid vehicle viscosity at $2 \mathrm{~N}$ load when considering in vitro swallowing of oblate (flattened) and prolate (elongated) spheroidal tablets of different aspect ratio (AR 0.25, 1.5 and 3.5). Theoretical curves are obtained using Eq. A.8 for a tablet diameter of $10 \mathrm{~mm}$.

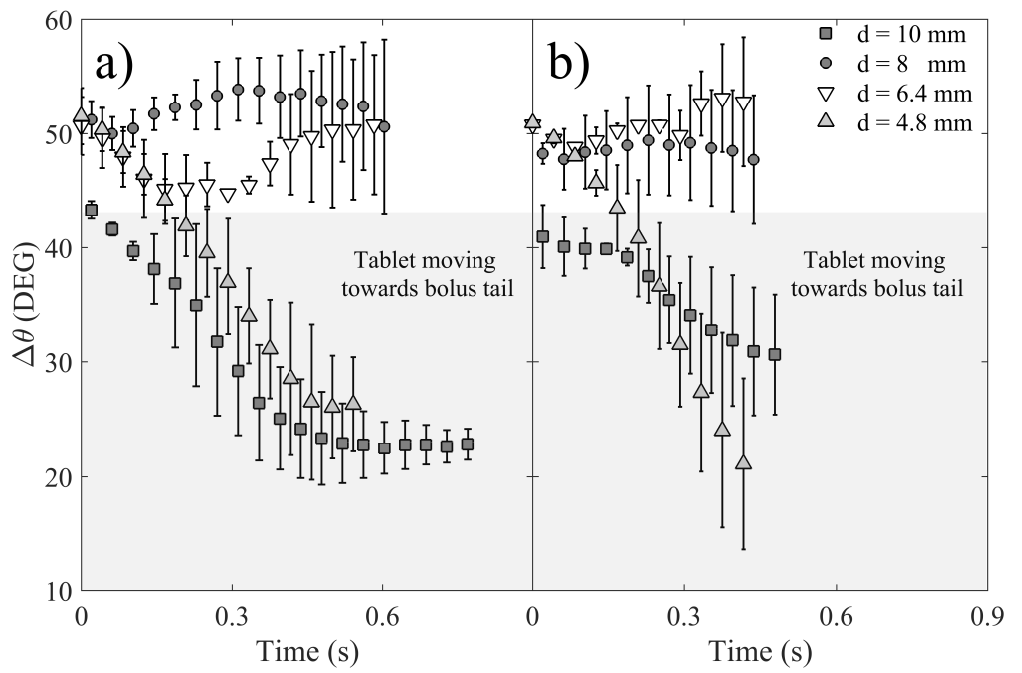

Figure 8: Angular distance between the bolus tail and the center of mass of spherical solid oral dosage forms using a $1.05 \mathrm{~Pa}$ s Newtonian liquid carrier at respectively a) $2 \mathrm{~N}$, and b) $2.7 \mathrm{~N}$ applied force. 


\subsection{In vitro swallowing of multiple tablets}

430

The relevant change in the measured in vitro oral dynamics was assessed when swallowing several tablets as a single unit dose. In these experiments the amount of liquid vehicle was kept consistent with the previous trials and the number of tablets was varied, according to their diameter, to deliver approximately an identical cumulative volume of solid oral medications. Beside a realistic volume fraction of solid oral medications of $\phi=0.08 \mathrm{v} / \mathrm{V}$, corresponding to a dose of $460-500 \mathrm{mg} / 6 \mathrm{~mL}$, using the in vitro model also allowed considering the effect of pushing the volume fraction to $\phi=0.15 \mathrm{v} / \mathrm{V}(920-960 \mathrm{mg} / 6 \mathrm{~mL})$.

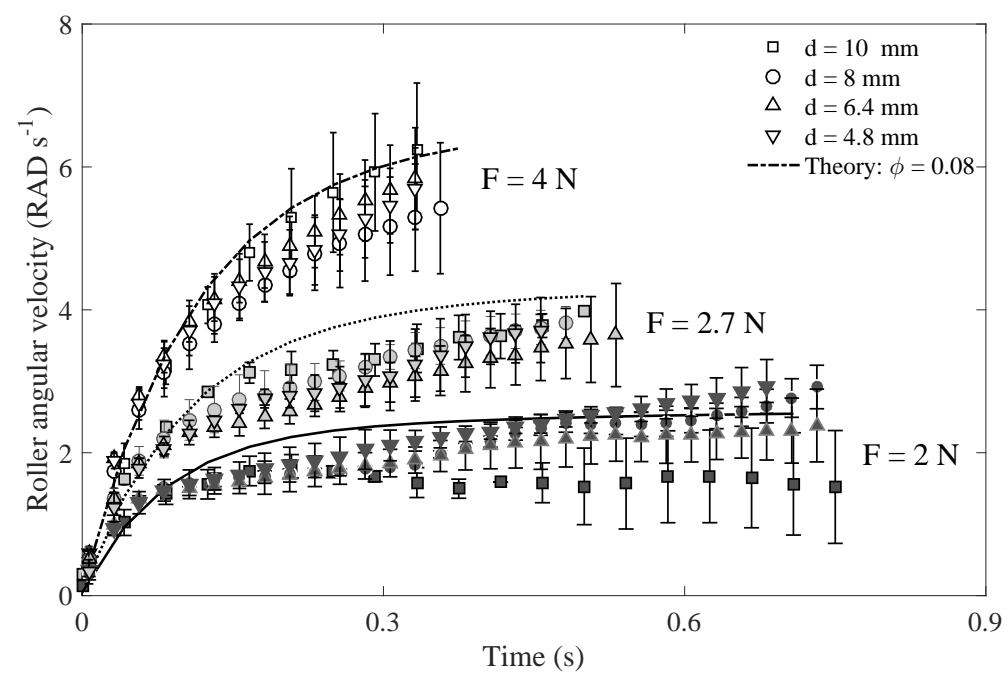

Figure 9: Effect of the particle size and applied force on the evolution of the angular velocity with time, at constant solid volume fraction $(\phi=0.08 \mathrm{v} / \mathrm{V})$ and using a $1.05 \mathrm{~Pa}$ s Netwonian liquid carrier. Theoretical angular velocity profiles obtained from Eq. A.9

Average velocity profiles at $\phi=0.08 \mathrm{v} / \mathrm{V}$, obtained from three repetitions for the different diameters and applied forces, are plotted in Fig. 9. The corresponding characteristic transit times reported in Table 4. The oral dynamics at low volume fraction of suspended solids was not strongly conditioned by the size of the spherical tablets when the system was operated under higher applied loads (2.7 and $4 \mathrm{~N}$ ). Decreasing the applied force to the mechanical system led to an increase in the oral transit time with the volumetric dose of suspended solids

${ }_{445} \phi$ for the tablet diameters here considered. In particular, driving the system with a more physiologically representative $2 \mathrm{~N}$ load resulted in velocity profiles that quickly reached a steady state where the viscous dissipation quantitatively equilibrated the applied force (Fig. 9p.

Increasing the suspended particle volume fraction to $\phi=0.15 \mathrm{v} / \mathrm{V}$ affected more significantly the flow of smaller tablets and accentuated the viscous dissipation leading to a lower steady state velocity and a faster onset of the steady 
Table 4: Characteristic oral transit times when swallowing a fixed dose of spherical tablets of different diameters in a $1.05 \mathrm{~Pa}$ s Newtonian liquid carrier.

\begin{tabular}{ccccc}
\hline $\begin{array}{c}\text { Applied } \\
\text { load }\end{array}$ & $\begin{array}{c}\text { Tablet } \\
\text { diameter }\end{array}$ & $\begin{array}{c}\text { Number of } \\
\text { tablets }\end{array}$ & $\begin{array}{c}\text { Average bolus FO } \\
(\mathrm{SD} \mathrm{n}=3)\end{array}$ & $\begin{array}{c}\text { Average bolus TO } \\
(\mathrm{SD} \mathrm{n}=3)\end{array}$ \\
\hline \multirow{2}{*}{$2 \mathrm{~N}$} & $4.8 \mathrm{~mm}$ & 9 & $0.69(0.04) \mathrm{s}$ & $0.91(0.04) \mathrm{s}$ \\
& $6.4 \mathrm{~mm}$ & 4 & $0.76(0.07) \mathrm{s}$ & $1.01(0.08) \mathrm{s}$ \\
& $8 \mathrm{~mm}$ & 2 & $0.75(0.08) \mathrm{s}$ & $0.99(0.09) \mathrm{s}$ \\
& $10 \mathrm{~mm}$ & 1 & $0.97(0.17) \mathrm{s}$ & $1.27(0.18) \mathrm{s}$ \\
\hline \multirow{2}{*}{$2.7 \mathrm{~N}$} & $4.8 \mathrm{~mm}$ & 9 & $0.48(0.02) \mathrm{s}$ & $0.68(0.03) \mathrm{s}$ \\
& $6.4 \mathrm{~mm}$ & 4 & $0.54(0.04) \mathrm{s}$ & $0.73(0.06) \mathrm{s}$ \\
& $8 \mathrm{~mm}$ & 2 & $0.50(0.02) \mathrm{s}$ & $0.68(0.03) \mathrm{s}$ \\
$4 \mathrm{~N}$ & $10 \mathrm{~mm}$ & 1 & $0.53(0.03) \mathrm{s}$ & $0.66(0.03) \mathrm{s}$ \\
\hline & $4.8 \mathrm{~mm}$ & 9 & $0.35(0.01) \mathrm{s}$ & $0.47(0.02) \mathrm{s}$ \\
& $8.4 \mathrm{~mm}$ & 4 & $0.36(0.02) \mathrm{s}$ & $0.47(0.03) \mathrm{s}$ \\
& $10 \mathrm{~mm}$ & 2 & $0.45(0.02) \mathrm{s}$ & $0.65(0.03) \mathrm{s}$ \\
\hline
\end{tabular}

state. This suggests that the fluid-solid interaction in presence of multiple beads increased significantly the drag force, hence leading to a reduction in the measured bolus velocity. This finding is somehow confirmed by the increased duration and area of the EMG bursts registered in vivo when swallowing multiple tablets, indicating the need for effortful swallows (Yamamoto et al. 2014).

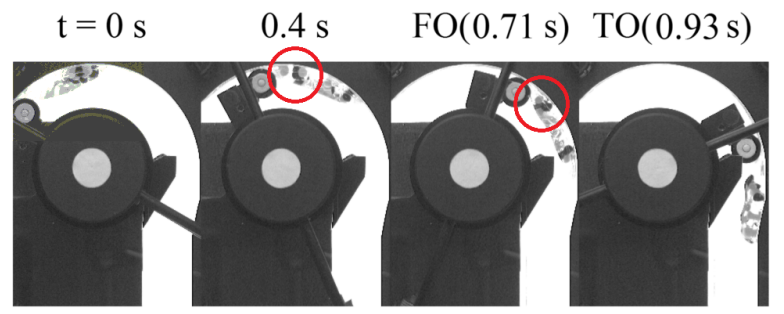

Figure 10: Screenshots from the in vitro experiment using a $2 \mathrm{~N}$ load and multiple spherical tablets $(\mathrm{d}=4.8 \mathrm{~mm}, \phi=0.08 \mathrm{v} / \mathrm{V})$ in a $1.05 \mathrm{~Pa} \mathrm{~s}$ Newtonian liquid carrier. Tablets moving towards the bolus tail are circled.

The increase in apparent liquid carrier viscosity predicted through the KriegerDougherty model (Eq. A.9) led to a slower theoretical dynamics, as can be appreciated comparing the results presented in Fig. 9 with those of Fig. 4 and Fig. 5 A good agreement between experimental results and theoretical values was found at low suspended solids volume fraction, however the theoretical model was incapable to capture the effect of particle size on the dynamics of the system. The experiments demonstrated that this effect was more significant at 
low applied forces or when the suspended phase volume fraction was increased.

Image analysis revealed that when the size of the solid oral dosage was reduced, these moved towards the tail of the bolus. This effect is qualitatively illustrated in Fig. 10 where clustering of suspended solids in proximity of the roller can be observed. The buildup of solids close to the roller resulted in a concentration gradient that limits the applicability of Eq. A.9. justifying the gap

470 between experimental data and theory. More sophisticated theoretical models are therefore needed to account for both the effect of solid oral dosage form size and dose. Particle image velocimetry could be used to study the bolus flow pattern, and numerical simulations, accounting for the full fluid-particle and particle-particle interaction, should be considered to model more accurately the 475 dynamic system.

In vivo, it can be speculated that the apparent backward motion of tablets, flowing towards the tip of the tongue, might lead the patient to interrupt the swallow or to masticate the tablets, instead of swallowing them whole. Studies in children show that the occurrence of chewing increases with the administrated 480 amount of mini-tablets, as already demonstrated by Kluk et al. (Kluk et al., 2015). In another study, that compared the ease of swallowing of mini-tablets $(\mathrm{d}=3 \mathrm{~mm})$ in respect of a conventional tablets $(\mathrm{d}=8 \mathrm{~mm})$, few of the healthy young participants were not able to swallow 10 mini-tablets with a single sip of water (Hayakawa et al. 2016). The result led the authors to conclude that

485 there is an optimal number of tablets above which the perceived attribute of ease of swallow with respect to conventional tablets deteriorates (Hayakawa et al. 2016). This highlights the need for understanding the bolus internal fluid dynamics in presence of multiple suspended particles that is key to support the design of novel solid oral medications that are easier to swallow.

490 With respect to tablet size, in vivo data from literature does not currently allow to complement the in vitro observations as comparable videofluoroscopy swallowing studies aiming at describing the dynamics of tablet swallowing are scarce. In one of these studies Kasashi et al. compared the effect of size for two different gelatin capsules (size 1 and size 4$)$ and density $\left(\rho_{S}=690-1370 \mathrm{~kg} \mathrm{~m}^{-3}\right.$ )

495 together with the patients' head position during swallowing (Kasashi et al. 2011). Their results indicate patient's preference towards swallowing smaller capsules that, irrespective of their density, lead to a statistically significant reduction in the oral transit time of the solid medication. The authors therefore suggest that the oral transit time may be effectively used to establish swallowing 500 preferences in patients (Kasashi et al., 2011). Numerous other sensory and hedonic reports have shown how the attribute of ease of swallowing for single tablets consistently increases, decreasing the size of the solid oral dosage forms (Liu et al., 2014). This observation is confirmed by the present experimental study that shows the negligible impact of small tablets on the oral swallowing 505 dynamics (Fig. 4 and Fig. 5).

Sensory trials with mini-tablets $(\mathrm{d}<4 \mathrm{~mm})$ showed a higher acceptability in children and newborns than other conventional types of oral delivery medications (i.e. syrup) (Liu et al., 2014, Klingmann et al., 2015, Mistry and Batchelor, 2017). This conclusion should however be put in relation to the viscosity of the 
different liquid vehicles used for tablet administration as it highly conditions the palatability and grittiness perception (Liu et al., 2014; Lopez et al., 2016). Therefore, examination of oral transit of similar solid oral dosage forms against liquid oral medicines would greatly benefit from a solid in vitro testing base.

An interesting future direction is to extend the in vitro experiment to consider also the pharyngeal and esophageal phases of swallowing which would enable to assess more holistically the impact of tablet formulation on all stages.

Finally, modeling the complex physics of salivary lubrication and wall interaction although outside the aim of the present study could constitute an important development in view of a more comprehensive description of wall friction and adhesion with the oral mucosa, following notable examples of in vitro works dealing with tablet adhesion to the esophagus (Cook and Khutoryanskiy, 2015).

\section{Conclusions}

This study investigated the effect of the presence of a single or multiple solid oral dosage forms in a peristaltic flow relevant for the oral phase of swallowing, to improve the understanding of the mechanical phenomena governing swallowing of tablets and capsules. The effect of tablet size, shape, volume fraction, and applied force were studied in a controlled and consistent way in an in vitro model experiment. Results at low to medium applied loads demonstrated that the dynamics of the bolus in presence of small, single spherical tablets did not exhibit significant variations with respect to the theoretical predictions in absence of any suspended solids. Conversely, the flow was more consistently slowed down when testing larger spherical tablets, especially at low driving forces. Increasing the applied driving force reduced the effect of the diameter of the swallowed solid and speeded up the dynamics.

The relative position between solid oral dosage forms and roller was also studied and it was found that small spherical solids steadily moved towards the tail of the bolus, whilst slightly bigger tablets $(\mathrm{d}=6.4$ and $\mathrm{d}=8 \mathrm{~mm})$ conserved their initial position relative to the bolus tail. Further increasing in the cross sectional diameter of the spherical tablet increased its friction against the in vitro oral cavity, ultimately causing the solid to lag behind the bolus. In vivo, it can be speculated that increased proximity with the tongue apex might result in a stronger perception of the presence of the solid oral medication.

The effect of solid oral dosage shape was considered using spheroids of different aspect ratios but identical volumes to those of two calibrated spherical

${ }_{545}$ tablets $(0.27$ and $0.52 \mathrm{~mL})$. Experiments show that using solids with smaller cross sections speeded up the dynamics of the bolus. This effect was only appreciable for the largest tablets and under low roller applied force, but it is accentuated with low viscosity liquid carriers. In the case of single tablets, the simple theoretical model proposed gives reasonably good predictions for small particles, but fails to capture the complex phenomena occurring when considering larger solid oral dosage forms, hence demonstrating the importance of considering in vitro experiments. 
The in vitro oral phase of swallowing was significantly slowed down when considering multiple suspended solids. Varying the size of the solid oral prescription changes their ability to pack. While larger tablets tended to align in the direction of flow, smaller tablets could also pack more closely in the width of the bolus. These differences limit the applicability of existing theories, in particular at higher volume fractions of suspended solids and provide further evidence supporting the use of in vitro experiments. Given the pharmaceutical 560 interest for new solid oral formulations, targeting the special needs of infants and elderly, the in vitro approach presented in this study could help screening novel formulations and help designing more targeted in vivo studies, before running in vivo investigations.

\section{Appendix A. Derivation of the theory}

The flow in the esophagus has previously been modeled considering a peristaltic flow in a duct (Brasseur, 1987; Li et al., 1990). In this type of geometry the progressive contraction and relaxation of the sphincters provides the pressure driving force for bolus transport. In the literature, the effect of peristaltic wave shape, type of pumped fluid and presence of single or multiple suspended solids

570 have been investigated showing an increase in particle velocity and displacement with particle diameter (Fauci, 1992, Hung and Brown, 1976). Although effective in modeling the simpler geometries of the esophagus and ureter, the extension of the peristaltic flow assumption to the oral cavity during swallowing finds several difficulties due to the more articulated lingual gestures. A simple model was nonetheless developed to evaluate the effect of viscosity during the in vitro swallowing of liquids without any suspended solid (Mowlavi et al., 2016). This mechanistic theory here synthetically considers the dynamics of the roller and of the bolus, driven by the external applied load and slowed down by the inertia and by the viscous dissipation in the bolus.

580 In the mechanical model used to simulate the oral phase of swallowing the total kinetic energy $K$ is made up by: 1) the roto-translational motion of the bolus (of mass $m_{B}$, linear velocity $v_{B}$, and inertia $I_{B}$ ), 2) the hanging weight (mass $M$ and linear velocity $v_{M}$ ), and 3 ) the rotation of the central assembly, of inertia $I$ at angular velocity $\dot{\theta}$ (Eq. A.1). Linear velocities can be put in relation to the angular velocity of the pulley $\theta$, knowing the radial distances from the center of rotation $r_{A}$ and $r_{P}$ (see Fig.2).

$$
K=\frac{1}{2}\left(m_{B} v_{B}^{2}+I_{B} \dot{\theta}^{2}\right)+\frac{1}{2} M v_{M}^{2}+\frac{1}{2} I \dot{\theta}^{2}
$$

The overall potential energy of the system $U$ is calculated from the displacement of the hanging mass and the vertical position of the bolus center of mass (Eq. A.2).

$$
U=M g \theta r_{P}+m_{B} g r_{A} \sin (\theta)
$$

Negative work on the system is done by the viscous dissipation $F_{d}$, tangential to the roller trajectory, and function of the angular velocity $\dot{\theta}$, the rheology of 
the liquid carrier $\mu$ and the geometry of the bolus. The equation of motion of the mechanical system, characterized by the single degree of freedom of angular rotation $\theta$, is obtained from the Lagrange equations of dynamics, where $\mathrm{Q}$ is the generalized force (Eq. A.4).

$$
\begin{gathered}
\frac{\mathrm{d}}{\mathrm{d} t}\left(\frac{\mathrm{d}}{\mathrm{d} \dot{\theta}}(K-U)\right)-\frac{\mathrm{d}}{\mathrm{d} \theta}(K-U)=Q \\
Q=\mathbf{F}_{\mathbf{d}} \cdot \frac{\partial \mathbf{x}}{\partial \theta}
\end{gathered}
$$

Substituting for $K$ and $U$ and after further rearrangement, an explicit relation to obtain the roller angular acceleration $\ddot{\theta}$ from geometrical and inertial properties is finally obtained.

$$
\ddot{\theta}=\frac{-F_{d} r_{A}+M g r_{P}+m g r_{A} \cos (\theta)}{I+I_{B}+m_{B} r_{A}^{2}+M r_{P}^{2}}
$$

Asymptotic analysis of Eq. A.5 predicts two different regimes of motion: at low angular velocities the contribution of viscous dissipation through Eq. A.7 becomes negligible and the dynamics of bolus swallowing is driven by the applied force and the inertia of the system, hence a constant angular acceleration is predicted. Conversely, when the magnitude of the viscous force becomes of the same order of magnitude of the moment of the driving force $\left(M g r_{P}\right)$ the numerator of Eq. A.5 vanishes and the motion of the bolus approaches constant values of angular velocity that justify the definition of $F_{d}$. The inertia of the central rotating assembly was determined once for all with empty runs of the device. Its value, being two orders of magnitude higher than that of the bolus led Hayoun et al. to consider it through a constant multiplication factor $\gamma>1$ ${ }_{610}$ to $I$ in Eq. A.5. Similarly a constant $F_{\min }$ was used to correct for the friction of the roller, as a minimum applied weight to the drive pulley of approx. $0.4 \mathrm{~N}$ was needed for the roller to start moving. In light of these latter observations the final form of Eq. A.5 was approximated by the following (Eq. A.6).

$$
\ddot{\theta}=\frac{-F_{d} r_{A}+\left(M g-F_{\min }\right) r_{P}+m_{B} g r_{A} \cos (\theta)}{\gamma I+I_{B}+m_{B} r_{A}^{2}+M r_{P}^{2}}
$$

The viscous force $F_{d}$ that appears in Eq. A.6 was assumed linearly proportional to the bolus velocity, obtained multiplying its angular velocity $\dot{\theta}$ by the radial distance of the roller from the center of rotation $r_{A}=47 \mathrm{~mm}$ (Mowlavi et al. 2016). A similar linear dependency holds at relatively low swallowing velocities, as comprehensively investigated by Mowlavi et al. (Mowlavi et al. 2016). A simple model for $F_{d}$ based on a Poiseuille flow assumption was used ${ }_{620}$ to predict the experimental bolus velocity profiles. Under this hypothesis, the bolus was idealized as cylindrical element of fluid of uniform cross section and length $L$ moving with an average velocity equal to the roller velocity (theta). This is consistent to the experimental observation that the length of the bolus is approximately constant during the flow. The resulting viscous force was com625 puted, considering the liquid viscosity $\mu$, via Eq. A.7. The constant $\beta=3.23$ 
was fitted on the experimental results to account for the system friction and is independent of the applied load and the fluid considered.

$$
F_{d}=\beta 8 \pi \mu L \dot{\theta} r_{A}
$$

The theory above was then extended considering the additional drag due to the particle interaction with the mean flow. Bungay and Brenner investigated 630 the case of close fitting particles in tubes (Bungay and Brenner, 1973), while Wang and Skalak (Wang and Skalak, 1969) studied the additional resistance in the case of a train of equally spaced spheres. The extension to the flow of spheroidal and cylindrical particles was presented by Chen and Skalak (Chen and Skalak, 1970) and more recently comprehensively described by Pozrikidis and Davis (Pozrikidis and Davis, 2013). Semi empirical correlations developed over a wide range of flow regimes in cylindrical tubes have also been proposed, in particular in the study of the pipeline flow of elongated capsules (Charles, 1963). Following the latter approach, a simple mathematical model considered the annular flow in the gap between the flowing solid (of cross sectional radius

$\left.{ }_{640} R_{i}=\mathrm{d} / 2\right)$ and the pipe radius $R_{e}$. In this geometry, the boundary conditions impose that the inner cylindrical solid (i.e. the solid oral dosage form) moves longitudinally with velocity equal to that of the roller $\dot{\theta} r_{A}$, while a no-slip condition was applied to the external shell (i.e. the plastic membrane in which the bolus was contained).

${ }_{645}$ Adapting the theory on experimental results in laminar flow conditions, Ellis found that the pressure drop experienced in transporting an infinitely long cylindrical neutrally buoyant object without axial offset, can be related to the pressure drop in a Poiseuille flow, with identical mean velocity, corrected by a factor dependent upon of the ratio of radii $k=R_{i} / R_{e}$ of the suspended solid and the pipe (Ellis, 1964). On this basis, the same correction was applied to relate the viscous dissipation of the bolus flow in presence of solid oral dosage forms to that of a Poiseuille flow.

$$
F_{d}=\left(1-k^{4}\right)^{-1} \beta 8 \pi \mu L \dot{\theta} r_{A}
$$

Eq. A.8 is consistent with the theory presented by Hayoun et al. when the cross sectional size of the tablet vanishes.

Finally, the flow of multiple suspended solids of volume fraction $\phi$ was modeled considering a correction term to the viscosity of the liquid carrier $(\mu)$ obtained from the Krieger-Dougherty model for spherical particles (Eq. A.9).

$$
F_{d}=\beta 8 \pi \mu\left(1-\frac{\phi}{\phi_{m}}\right)^{-2.5 \phi_{m}} L \dot{\theta} r_{A}
$$

The solid volume fraction $\phi_{m}$ was considered that of a random close packing of particles $\left(\phi_{m}=0.64\right)$ (Hiemenz and Rajgopalan, 1997). 


\section{References}

Alsanei AS. Tongue Pressure - A Key Limiting Aspect in Bolus Swallowing Woroud Abdulrahman Saleh Alsanei. Ph.D. thesis; University of Leeds; 2015.

Batchelor H, Venables R, Marriott J, Mills T. The application of tribology in assessing texture perception of oral liquid medicines. International Journal of Pharmaceutics 2015;479(2):277-81.

Brasseur JG. A fluid mechanical perspective on esophageal bolus transport. Dysphagia 1987;2(1):32-9.

Brotherman DP, Bayraktaroglu TO, Garofalo RJ. Comparison of ease of swallowing of dietary supplement products for age-related eye disease. Journal of the American Pharmacists Association 2004;44(5):587-93.

Bungay PM, Brenner H. The motion of a closely-fitting sphere in a fluid-filled tube. International Journal of Multiphase Flow 1973;1(1):25-56.

Channer KS, Virjee JP. The effect of size and shape of tablets on their esophageal transit. Journal of clinical pharmacology 1986;26(2):141-6.

Charles ME. The pipeline flow of capsules: Part 2: Theoretical analysis of the concentric flow of cylindrical forms. The Canadian Journal of Chemical Engineering 1963;41(2):46-51.

Chen TC, Skalak R. Stokes flow in a cylindrical tube containing a line of spheroidal particles. Applied Scientific Research 1970;22(1):403-41.

so Cook MT, Khutoryanskiy VV. Mucoadhesion and mucosa-mimetic materialsA mini-review. International Journal of Pharmaceutics 2015;495(2):991-8.

Diamond S, Lavallee DC. Experience with a pill-swallowing enhancement aid. Clinical pediatrics 2010;49(4):391-3.

Ellis HS. The pipeline flow of capsules: Part 3 - An experimental investigation of the transport by water of single cylindrical and spherical capsules with density equal to that of the water. The Canadian Journal of Chemical Engineering 1964;42(1):1-8.

Fauci LJ. Peristaltic pumping of solid particles. Computers Fluids 1992;21(4):583-98.

690 FDA . Dissolution Testing of Immediate Release Solid Oral Dosage Forms. Guidance for Industry 1997;4.

FDA . Size, Shape and Other Physical Attributes of Generic Tablets and Capsules. Guidance for Industry 2013;12.

Fields J, Go JT, Schulze KS. Pill Properties that Cause Dysphagia and Treatment Failure. Current Therapeutic Research - Clinical and Experimental 2015;77:79-82. 
Groher ME. Normal Swallowing in Adults. In: Dysphagia. Elsevier; 2nd ed.; 2016. p. 19-40.

Hayakawa Y, Uchida S, Namiki N. Evaluation of the ease of taking mini-tablets compared with other tablet formulations in healthy volunteers. European Journal of Pharmaceutical Sciences 2016;84:157-61.

Hayoun P, Engmann J, Mowlavi S, Le Reverend B, Burbidge A, Ramaioli M. A model experiment to understand the oral phase of swallowing of Newtonian liquids. Journal of Biomechanics 2015;48(14):3922-8.

Hey H, Jørgensen F, Sørensen K, Hasselbalch H, Wamberg T. Oesophageal transit of six commonly used tablets and capsules. British medical journal 1982;285:1717-9.

Hiemenz PC, Rajgopalan R. Principles of Colloid and Surface Chemistry. 3rd ed. CRC Press, 1997.

Hung TK, Brown TD. Solid-particle motion in two-dimensional peristaltic flows. Journal of Fluid Mechanics 1976;73(01):77.

Jagani M, Legay H, Ranmal SR, Bertrand J, Ooi K, Tuleu C. Can a Flavored Spray (Pill Glide) Help Children Swallow Their Medicines? A Pilot Study. Pediatrics 2016;138(6).

715 Kasashi K, Tei K, Totsuka Y, Yamada T, Iseki K. The influence of size, specific gravity, and head position on the swallowing of solid preparations. Oral Science International 2011;8(2):55-9.

Kelly J, D'Cruz G, Wright D. Patients with dysphagia: Experiences of taking medication. Journal of Advanced Nursing 2010;66(1):82-91.

${ }_{720}$ Klingmann V, Seitz A, Meissner T, Breitkreutz J, Moeltner A, artin Bosse HM. Acceptability of Uncoated Mini-Tablets in Neonates-A Randomized Controlled Trial. The Journal of pediatrics 2015;167(4):893-6.

Kluk A, Sznitowska M, Brandt A, Sznurkowska K, Plata-Nazar K, Mysliwiec M, Kaminska B, Kotlowska H. Can preschool-aged children swallow several minitablets at a time? Results from a clinical pilot study. International Journal of Pharmaceutics 2015;485(1):1-6.

Leonard R, Katerine K. Dysphagia assessment and treatment planning: a team approach. Plural Publishing, 2008.

Li M, Brasseur J, Dodds W. Nonsteady model of peristaltic transport applied to swallowing. In: Sixteenth Annual Northeast Conference on Bioengineering. IEEE; 1990. p. 58-9. 
Liu F, Ranmal S, Batchelor HK, Orlu-Gul M, Ernest TB, Thomas IW, Flanagan T, Tuleu C. Patient-centred pharmaceutical design to improve acceptability of medicines: Similarities and differences in paediatric and geriatric populations. Drugs 2014;74(16):1871-89.

Lopez FL, Bowles A, Gul MO, Clapham D, Ernest TB, Tuleu C. Effect of formulation variables on oral grittiness and preferences of multiparticulate formulations in adult volunteers. European Journal of Pharmaceutical Sciences 2016;92:156-62.

740 Lopez FL, Ernest TB, Tuleu C, Gul MO. Formulation approaches to pediatric oral drug delivery: benefits and limitations of current platforms. Expert Opinion on Drug Delivery 2015;12(11):1727-40.

Manrique YJ, Lee DJ, Islam F, Nissen LM, Cichero JAY, Stokes JR, Steadman KJ. Crushed tablets: Does the administration of food vehicles and thickened fluids to aid medication swallowing alter drug release? Journal of Pharmacy and Pharmaceutical Sciences 2014;17(2):207-19.

Meltzer EO, Welch MJ, Ostrom NK. Pill Swallowing Ability and Training in Children 6 to 11 Years of Age. Clinical Pediatrics 2006;45(8):725-33.

Mistry P, Batchelor H. Evidence of acceptability of oral paediatric medicines: a review. Journal of Pharmacy and Pharmacology 2017;69(4):361-76.

Mowlavi S, Engmann J, Burbidge A, Lloyd R, Hayoun P, Le Reverend B, Ramaioli M. In vivo observations and in vitro experiments on the oral phase of swallowing of Newtonian and shear-thinning liquids. Journal of Biomechanics 2016;49(16):3788-95.

Overgaard B, Højsted J, Hansen R, Christrup L. Patient's evaluation of shape, size and colour of solid dosage forms. Pharmacy World and Science 2001;23(5):185-8.

Pozrikidis C, Davis JM. Resistance and pressure coefficients for a periodic array of spherical, spheroidal, and cylindrical particles inside a circular tube. Journal of Applied Mathematics 2013;78(1):32-58.

Radhakrishnan C. Oral medication dose form alteration: Patient factors and the effects of adding thickened fluids. Ph.D. thesis; University of Queensland; 2016.

Ren J, Hofmann CL, Kern MK, Arndorfer RC, Shaker R. Kinematic and Dynamic Characteristics of Solid Pellet Movement during the Pharyngeal Phase of Swallowing. Annals of Otology, Rhinology \& Laryngology 1996;105(9):71623.

Salmon D, Pont E, Chevallard H, Diouf E, Tall ML, Pivot C, Pirot F. Pharmaceutical and safety considerations of tablet crushing in patients undergoing enteral intubation. International Journal of Pharmaceutics 2013;443(1):14653. 
Schiele JT, Penner H, Schneider H, Quinzler R, Reich G, Wezler N, Micol W, Oster P, Haefeli WE. Swallowing Tablets and Capsules Increases the Risk of Penetration and Aspiration in Patients with Stroke-Induced Dysphagia. Dysphagia 2015;30(5):571-82.

Slavkova M, Breitkreutz J. Orodispersible drug formulations for children and elderly. European Journal of Pharmaceutical Sciences 2015;75:2-9.

Stegemann S, Gosch M, Breitkreutz J. Swallowing dysfunction and dysphagia is an unrecognized challenge for oral drug therapy. International Journal of Pharmaceutics 2012;430(1-2):197-206.

Stubbs J, Haw C, Dickens G. Dose form modification a common but potentially hazardous practice. A literature review and study of medication administration to older psychiatric inpatients. International Psychogeriatrics 2008;20(03):616-27.

Thomson SA, Tuleu C, Wong ICK, Keady S, Pitt KG, Sutcliffe AG. Minitablets: New Modality to Deliver Medicines to Preschool-Aged Children. Pediatrics $2009 ; 123(2): 235-8$.

Wang H, Skalak R. Viscous flow in a cylindrical tube containing a line of spherical particles. Journal of Fluid Mechanics 1969;38:75-96.

790 Wilson CG, Washington N, Washington C. Drug Delivery to the Oral Cavity and Mouth. In: Physiological Pharmaceutics Barriers to Drug Absorption. CRC Press; 2000. p. 37-57.

Yamamoto S, Taniguchi H, Hayashi H, Hori K, Tsujimura T, Nakamura Y, Sato H, Inoue M. How do tablet properties influence swallowing behaviours? Journal of Pharmacy and Pharmacology 2014;66(1):32-9. 